\title{
ESTIMATION OF DISTANCE OF SINGING CONSPECIFICS BY THE CAROLINA WREN
}

\author{
Douglas G. RichaRdS ${ }^{1}$ \\ Department of Zoology, University of North Carolina, Chapel Hill, North Carolina 27514 USA
}

\begin{abstract}
Measurements of the propagation of sound in a forest have shown that signal degradation is unavoidable but to some degree predictable. Carolina Wrens (Thryothorus ludovicianus) have a song structure suited for the estimation of distance by a comparison of the relative degradation of the components of the signal. Playback experiments using song recorded at two distances from a singing wren demonstrated that wrens can use cues other than the absolute attentuation of the sound for the estimation of the distance of the singer. The wrens responded to the near-sounding song by attack and to the far-sounding song by countersinging. The ability of the wrens to use the distance information in the song serves the same purpose as the recognition of familiar neighbors: conservation of time and energy used in territorial defense. Received 26 November 1979, accepted 22 August 1980.
\end{abstract}

SEVERAL recent studies have investigated the effects of the acoustics of the environment in constraining the structure of the songs used for long-distance communication in passerine birds. Passage through the environment degrades a song by adding amplitude fluctuations and reverberations and selectively attenuating the higher frequencies. Measurements of the propagation of sound in a forest have shown that signal degradation is unavoidable but to some degree predictable (Morton 1970, 1975; Chappuis 1971; Marten and Marler 1977; Marten et al. 1977; Richards 1978; Wiley and Richards 1978; Richards and Wiley 1980). The primary concern of most researchers has been to discover those characteristics of the structure of bird song adapted for transmitting information (primarily species and individual identity) over the greatest distance. In this study I demonstrate another adaptation of birds to song degradation: the use of the predictability of the degradation present in received signals for estimation of the distance of a conspecific signaler by the Carolina Wren (Thryothorus ludovicianus).

It seems likely that individuals of many avian species are not spaced far enough apart to place strong constraints on the structure of their signals for long-range communication. Though the territory of a breeding bird may be $100 \mathrm{~m}$ in diameter, the bird moves around the territory while singing, frequently changing the spacing between itself and its neighbors. To discriminate between an invader inside the territory and a neighbor or other bird outside without wasting energy in a physical interaction, an individual would do well to attend to the features in the received signal that are correlated with the distance of the signaler. The overall attenuation of the received signal, however, is probably not the best cue for the distance of the source, because changes in weather would strongly affect atmospheric absorption and scattering from microclimatic heterogeneities (Wiley and Richards 1978). Much more reliable ranging would result from comparing separate features of the received signal, either different frequency bands or different periodicities of intensity in any one band.

One possibility for ranging would involve comparing the received intensities of

\footnotetext{
${ }^{1}$ Present address: Kewalo Basin Marine Mammal Laboratory, University of Hawaii, 1129 Ala Moana Boulevard, Honolulu, Hawaii 96814 USA.
} 
high- and low-frequency components of a signal. Because high frequencies attenuate faster, owing to higher absorption and scattering, a receiver that knew the spectral structure of a signal at the source could judge its distance by the relative attenuation of high frequencies. In addition, because reverberations and random amplitude fluctuations increase with carrier frequency (Richards and Wiley 1980), a receiver might compare reverberations or amplitude fluctuations of a high- and a low-frequency component in the signal. To allow such ranging, a signal should include either a variety of rates of amplitude modulation or variation in the carrier frequency. The songs of many passerine birds contain wide frequency sweeps and have considerable energy in frequencies outside the optimum band for minimum attenuation over a distance (Richards and Wiley 1980).

The song of the Carolina Wren, described by Borror (1956) and Richards (1978), has an ideal structure for allowing the estimation of the distance of a signaler (Fig. 1). It consists of repeated syllables, each containing two or more notes. Notes include both relatively pure tones and sharp, frequency-modulated sweeps. The repetition rate varies but is usually slow enough to allow discrimination of the individual notes and the following reverberation under moderately reverberant conditions. The frequency sweeps allow a comparison of frequency-dependent attenuation.

For an experimental demonstration of distance estimation, it is necessary that the study species have different responses to near and distant song that can be discriminated. Field observations of Carolina Wrens revealed countersinging and occasional theme matching with distant conspecifics; playbacks of undegraded song near a territory holder usually caused a cessation of singing and an immediate silent attack.

In this experiment $I$ show that, independent of intensity cues, a Carolina Wren can discriminate between near and distant song from playback tapes and behave appropriately. This experiment mimics the natural situations of invader-within-territory and nonthreatening bird outside.

\section{MethodS}

The Carolina Wren is a nonmigratory species found throughout the eastern United States, primarily south of New England, though its range has been steadily extended northward during this century (Bent 1948). The birds pair-bond monogamously and defend territories. Only the male sings, but the female occasionally joins in with a churring call (see Laskey 1948, Nice and Thomas 1948, Luther 1974, and Morton and Shalter 1977 for more detail on general behavior). Each individual has more than 22 different song themes, many shared generally in the population. A territorial male sings in bouts of a given song theme, then switches to another song theme after several minutes. Frequently, neighboring males will match themes. No study has yet been published on the parameters of song influencing species recognition in this species.

Playback experiments. - The test songs were recorded from a bird in the same population as the subjects but that was not a neighbor of any of those birds. Many themes are shared in the population, and there is a great diversity of themes (Richards 1978), so individual recognition of the song as that of a neighbor would be unlikely in any case. Most of the birds tested were probably familiar with the theme, one of those more commonly heard.

I used two recordings of the same song theme for the playback, one with minimal degradation, recorded about $10 \mathrm{~m}$ from a singing Carolina Wren and referred to hereafter as the NEAR song, and one with considerable degradation, recorded at about $50 \mathrm{~m}$ from the same wren and referred to as the FAR song (Fig. 1). Both were recorded with a Sennheiser MKH815T directional microphone on a Nagra 4.2 tape recorder at $19 \mathrm{~cm} / \mathrm{s}$. For playback, the sounds were re-recorded on the two channels of a stereo tape. One channel had the NEAR song, the other channel the FAR song, repeated at $12 \mathrm{songs} / \mathrm{min}$. I could switch instantly from one track to the other on the Uher 4200 Report Stereo IC tape recorder used for playback. The peak levels of the NEAR and FAR songs were adjusted identically during production of the playback tape, and the background noise level (intensity of the baseline preceding the song on the 
$\mathrm{kHz}$ A

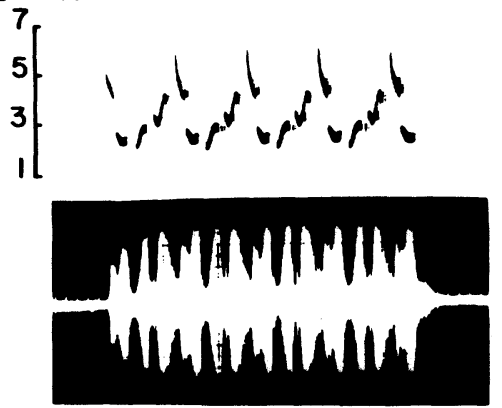

B
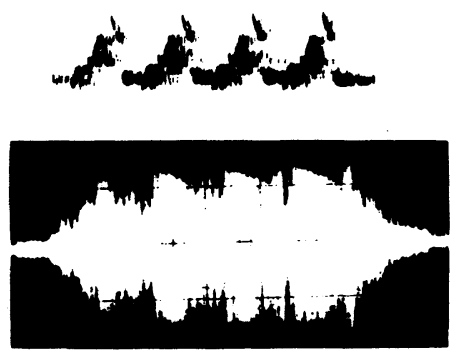

Fig. 1. Spectrograms (above) and oscillograms (below) of recordings of the song of a Carolina Wren used for playback: A, recorded $10 \mathrm{~m}$ from the singing bird; B, recorded $50 \mathrm{~m}$ from the singing bird; time mark is $0.5 \mathrm{~s}$.

oscillogram) was very low in both cases, as can be seen in the oscillograms in Fig. 1. The speaker was an omnidirectional Poly Planar speaker placed about $8 \mathrm{~m}$ from the observer, $25 \mathrm{~m}$ from the bird, and $1 \mathrm{~m}$ above the ground. During the actual experiment the volume control on the Uher was always set at the same position in both the NEAR and FAR conditions. I set the loudness level during preliminary experiments as a compromise between the softest NEAR level that could attract a bird and the loudest FAR level that would elicit countersinging without approach. The peak levels for both tapes, measured at $1 \mathrm{~m}$ from the speaker with a General Radio Type $1551-\mathrm{C}$ sound level meter, were within $1 / 2 \mathrm{~dB}$. The absolute sound level, determined later under conditions similar to those during the playback experiments, was $78 \mathrm{dBA}$ at $1-\mathrm{m}$ distance on the fast response setting.

Playing even rather distorted wren songs long enough will cause a wren to approach and investigate. It can use such cues as the apparent degree of scattering of the direction of the sound to estimate distance (Wiley and Richards 1978). I therefore needed to use a short enough playback period that the bird would have no chance to compare multiple cues about distance and perceive the lack of agreement. Determining distance using the degree of scattering of the apparent locus of the sound requires movement of the bird's head to determine the spread of the beam and takes more time than the perception of reverberation and frequency dependent attenuation.

In preliminary experiments with a singing wren at about $25 \mathrm{~m}$, the wren would usually cease singing and approach the undegraded song within $1 \mathrm{~min}$. After a minute of attack and flight in proximity to the sound source, it would often begin to sing again. During the playback of degraded song, the bird usually needed more than a minute to perceive that the sound source was actually near and to approach. Before approach, the bird would usually continue to sing and occasionally switch to match the theme on the playback tape.

I therefore arrived at the following sequence for the playback experiment (the order of presentation was not randomized, see below).

(1) 1 min preplay. To be certain of the location of the subject I began each experiment after hearing a minute of continuous singing by the bird at $9-14$ songs/min. I placed the speaker $25 \mathrm{~m}$ away from the singing bird, toward the center of his territory.

(2) 1 min playback of the FAR song. Expected response: continued singing and possible theme matching.

(3) 1 min period with no playback.

(4) 1 min playback of the NEAR song. Expected response: cessation of singing, attack on speaker.

(5) 1 min period with no playback.

This experiment was performed in 1977 with five birds, each receiving either three or four playbacks for a total of 18 trials. Each experiment involved only 2 min of total playback to the subject, which made habituation during the experiment very unlikely. Occasionally, the same bird was tested more than once in a single day, but it had always recovered its spontaneous singing behavior and was $25 \mathrm{~m}$ from the speaker. I conducted these experiments in the North Carolina Botanical Garden (NCBG) and the Umstead Recreation area in Chapel Hill, North Carolina. For the experiments in the NCBG plot, I had a grid of 25-m squares to help with accurate measurement of distance. In other areas, I estimated distance by eye and ear. 
Ideally, the order of playback of the two tapes should be balanced or randomized to control for effects of order (Wiley and Wiley 1977). This was not possible in these experiments; hearing the NEAR song, the bird would locate the speaker, approach, and remain in the area for a length of time after the playback. Because the bird now knew the location of the speaker, a subsequent FAR playback would attract it quickly.

It was therefore necessary to determine whether or not the approach response to the NEAR playback could have been due to a priming effect of having first heard the FAR playback. In 1978 I played the NEAR song alone to six singing wrens (not necessarily the same individuals as in 1977 , though several were on the same sites) for a total of 18 trials and measured their response on the same scale as in the FAR/NEAR experiments. I sought to demonstrate that the unprimed response to the NEAR song was not significantly different from the response to the NEAR song following a minute of FAR playback. This experiment is designated NEAR CONTROL in Table 1 and Fig. 2.

To demonstrate that the FAR song was capable of eliciting a species-specific response, I also did playbacks at full volume to wrens not spontaneously singing. I divided each playback period into three segments, a 5-min preplay to quantify a baseline for the subject's behavior, a 5-min playback, and a 5-min postplay period. The 5-min length was necessary to demonstrate that little response occurred within the first minute, the time allotted in the FAR/NEAR experiment, but that several more minutes of FAR song would elicit a response. The response measure used for the statistics was the number of songs during the playback period compared to the number of songs during the preplay period.

Scoring responses. - In most song recognition experiments (those in Richards 1979, for example), the response measurement is a continuous scale from low to high intensity. Here I needed to discriminate between two qualitatively different types of response, which also intergraded to some degree, making it impossible to use simple nominal categories. I designated a scale with the strongest, most unambiguous form of each response at opposite ends; toward the middle are the intergrading weaker forms. The scale ranged from -5 , the maximum response to a FAR song (matching the playback), to +5 , the maximum response to NEAR song (physical attack on the speaker):

+2 points for approach within $5 \mathrm{~m}$ of the speaker.

+1 point for being within $5 \mathrm{~m}$ at least $50 \%$ of the minute.

+1 point for two or more flights in the vicinity of the speaker.

+1 point for attack on the speaker.

$=+5$ points for the strongest NEAR response.

-1 point for more than $5 \mathrm{~m}$ from the speaker throughout playback minute.

-3 points for singing: 2 points for $3-8$ songs; 3 points for 8 or more songs.

-1 point for switching song theme to match playback theme.

$=-5$ points for the strongest FAR response.

The values in the scale are roughly based on the amount of energy expended by the bird in performing the specific behavior. Note, however, that the purpose of the scale is not primarily to discriminate high from low intensity, but rather to discriminate NEAR from FAR. The point values were arbitrarily assigned to achieve maximum separation of these qualities by the scale, based on the behaviors of wrens in preliminary experiments. I analyzed the paired comparisons nonparametrically.

To calculate the total response score, I added the points for each behavior witnessed. For example, a bird that sang five songs $(-2)$, then approached to within $5 \mathrm{~m}(+2)$ and attacked $(+1)$, but was not in the area for $50 \%$ or more of the time received a total score of +1 . A bird that ceased singing, approached to within $5 \mathrm{~m}(+2)$ and flew four times in the vicinity of the speaker $(+1)$, but did not attack and was not within $5 \mathrm{~m} 50 \%$ or more of the minute received a score of +3 . Thus individuals responding with behaviors typical of response to both NEAR and FAR song received scores near the middle of the scale.

\section{Results}

An actively singing wren typically responded to the FAR playback by continuing to sing and occasionally matching themes (matching occurred twice out of 18 trials). Wrens typically responded to the NEAR playback by ceasing singing and approaching the speaker, sometimes physically attacking it. The response to the NEAR playback was more variable than that to the FAR playback, with a slight indication of bimodality in the distribution of scores. In terms of the actual behavior, sometimes 


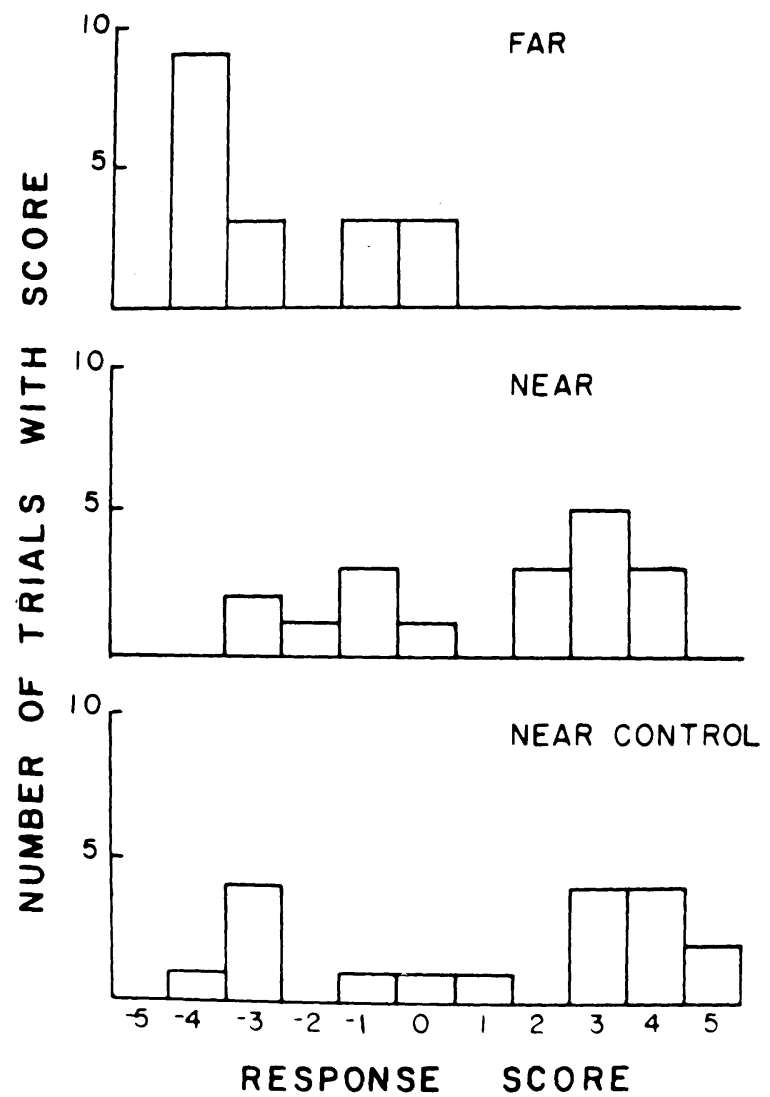

Fig. 2. Distributions of response scores for FAR, NEAR, and NEAR CONTROL playbacks to Carolina Wrens.

a bird would continue singing and attack at the same time in response to the NEAR playback. In most cases, however, the birds that attacked and continued to sing to the NEAR playback had continued singing but had not attacked in response to the FAR playback.

Figure 2 presents the distribution of response scores for the FAR and NEAR playbacks. Owing to the nature of the differences in response and the non-normal shape of the distributions, I compared the pairs of responses in each experiment with a Wilcoxon Matched-pairs Signed-ranks Test (Hays 1973). The difference between the FAR and NEAR playback conditions was significant in the expected direction at $P<0.001$ (see Table 1 for matched-pairs data).

The control playback for the NEAR song alone did not elicit responses significantly different from the NEAR song following the FAR song (Mann-Whitney $U$-Test, Hays 1973). Figure 2 shows that the responses to the NEAR song in this control were also quite variable; occasionally, the bird would countersing before approaching or would not approach at all and thus would receive a score in the middle range.

The playback of $5 \mathrm{~min}$ of full-volume FAR song elicited a song response significantly greater than the baseline level (mean number of songs $=24, P<0.02, n=$ 8, Wilcoxon Matched-pairs Signed-ranks test, Hays 1973). The mean latencies to 
TABLE 1. Comparison of responses in FAR/NEAR/NEAR CONTROL experiment.

\begin{tabular}{lccc}
\hline \hline \multicolumn{1}{c}{ Comparison } & $T^{\mathrm{a}}$ or $U^{\mathrm{b}}$ & $P$ & $n$ \\
\hline NEAR vs. FAR & 1.5 & $<0.001^{\mathrm{a}}$ & 17 \\
NEAR vs. FAR & 36 & $<0.001^{\mathrm{b}}$ & 18,18 \\
NEAR vs. NEAR CONTROL & 150 & ns $^{\mathrm{b}}$ & 18,18 \\
FAR vs. NEAR CONTROL & 49.5 & $<0.002^{\mathrm{b}}$ & 18,18 \\
\hline
\end{tabular}

a Wilcoxon Matched-pairs Signed-ranks Test (Hays 1973).

${ }^{b}$ Mann-Whitney $U$-Test (Hays 1973).

both song (180 s $\pm 150 \mathrm{SD})$ and approach $(255 \mathrm{~s} \pm 225 \mathrm{SD})$ were both greater than $1 \mathrm{~min}$.

\section{Discussion}

The results confirm the hypothesis that Carolina Wrens can use information from degraded songs to judge distance independently of the absolute loudness of the song. The wrens tended to react to the degraded song as they would to a bird outside their territories and to the undegraded song as they would to an invader.

In any experiment of this type, it is difficult to separate low attack motivation from inability to recognize the song as conspecific, because the usual measure of recognition is the strength of aggressive response. The appropriate response to a distant-sounding playback is not immediate attack; it should be behaviors (calling, singing, cautious approach) allowing the territory holder to confirm species identity and to estimate the magnitude of the threat from the other bird without wasting energy.

There are several lines of evidence to show that the characteristic response to the FAR song is not simply an inability to hear the playback or recognize it as conspecific. First, the distance to the bird at the beginning of the playback $(25 \mathrm{~m})$ was always known, and the playback level was loud enough for the bird to hear. Sufficient volume is confirmed by the rapid approach of the birds to a NEAR playback at the same volume. The direct evidence of recognition of the FAR song is that in two instances the wrens switched themes to match the playback. This is too small a sample for statistical analysis, but, considering the large number of potential themes and the tendency of the wrens to sing in bouts of a single theme for a period of time, it is unlikely that switching to the playback theme would occur by chance during the 1 min playback period. The indirect evidence is that birds countersing to distant wrens under spontaneous field conditions. The playback tape was recorded from $50 \mathrm{~m}$ away; often neighbors are twice as far away. Finally, the 5-min playback of the FAR song to birds not spontaneously singing could stimulate the birds to sing and approach with long latency.

The ability of the wren to use the distance information in the song serves the same purpose as recognition of familiar neighbors: conservation of time and energy used in territorial defense. The important point is the ability to discriminate an invader requiring an immediate response from a nonthreatening distant bird. Given the variability in absolute attenuation of sound (see Morton 1975, Marten and Marler 1977, Marten et al. 1977, Wiley and Richards 1978), it is to the birds' advantage to use the multiple cues provided by reverberation and frequency-dependent attenuation to estimate distance. Future research could concentrate on the exact cues in the signal degradation used by the bird for distance estimation. 


\section{ACKNOWLEDGMENTS}

I thank R. H. Wiley, H. C. Mueller, and E. S. Morton for comments on earlier drafts of this manuscript. This work was supported in part by a grant from the Frank M. Chapman Memorial Fund of The American Museum of Natural History.

\section{Literature Cited}

Bent, A. C. 1948. Life histories of North American nuthatches, wrens, thrashers and their allies. U.S. Natl. Mus. Bull. 195: 205-217.

Borror, D. J. 1956. Variation in Carolina Wren songs. Auk 73: 211-229.

Chappuis, C. 1971. Un exemple de l'influence du milieu sur les émissions vocales des oiseaux: l'évolution des chants en forêt équatoriale. Terre et Vie 118: 183-202.

Hays, W. L. 1973. Statistics for the social sciences. New York, Holt, Rinehart, and Winston, Inc.

Laskey, A. R. 1948. Some nesting data on the Carolina Wren at Nashville, Tennessee. Bird-Banding 19: $101-121$.

Luther, D. H. 1974. Observations at a Carolina Wren nest from which Brown-headed Cowbirds fledged. Wilson Bull. 86: 51-57.

Marten, K., \& P. Marler. 1977. Sound transmission and its significance for animal vocalization. I. Temperate habitats. Behav. Ecol. Scoiobiol. 2: 271-290.

, D. Quine, \& P. MARLER. 1977. Sound transmission and its significance for animal vocalization.

II. Tropical forest habitats. Behav. Ecol. Sociobiol. 2: 291-302.

Morton, E. S. 1970. Ecological sources of selection on avian sounds. Unpublished Ph.D. dissertation, New Haven, Connecticutt, Yale Univ.

1975. Ecological sources of selection on avian sounds. Amer. Natur. 109: 17-34.

M. D. Shalter. 1977. Vocal response to predators in pair-bonded Carolina Wrens. Condor 79: 222-227.

Nice, M. M., \& R. H. Thomas. 1948. A nesting of the Carolina Wren. Wilson Bull. 60: 139-158.

RICHARDS, D. G. 1978. Environmental acoustics and song communication in passerine birds. Unpublished Ph.D. dissertation, Chapel Hill, North Carolina, Univ. North Carolina.

- 1979. Recognition of neighbors by associative learning in Rufous-sided Towhees. Auk 96: 688693.

, \& R. H. WILEY. 1980. Reverberations and amplitude fluctuations in the propagation of sound in a forest: implications for animal communication. Amer. Natur. 115: 381-399.

Wiley, R. H., \& D. G. Richards. 1978. Physical constraints on acoustic communication in the atmosphere: implications for the evolution of animal vocalizations. Behav. Ecol. Sociobiol. 3: 69-94. , \& M. S. Wiley. 1977. Recognition of neighbor's duets by Stripe-Backed Wrens, Camphlorhynchus nuchalis. Behaviour 62: 10-34. 